\title{
ГИБКИЕ КОМПЛЕКСЫ ДЛЯ УПРАВЛЕНИЯ СУДОВОЙ ЭНЕРГЕТИЧЕСКОЙ УСТАНОВКИ
}

\section{FLEXIBLE SYSTEMS FOR CONTROLLING A MARINE POWER PLANT}

\section{Brezhnev}

Summary. The article provides an overview of the disclosure of modern network management capabilities of the entire ship's power plant using heterogeneous networks, DUAL LAN, FIBER OPTIC, DUAL CAN, Modbus, as well as individual unit elements through network capabilities through the central post, engine room post, additional posts, energy management post. The necessity of using network control for the smooth regulation of the technological process by means of instrumentation, actuators connected to control modules is substantiated.

The modern features of the application of network monitoring of a twostroke engine without camshafts operating on a screw, where instead of a camshaft are used electromagnetic actuators and a four-stroke using a modern azipode-type helical steering column, where the electric motor is located in a handball, which allows flexible screw control, are shown., generators and engines using heterogeneous networks. The use of servernetwork technologies in power plants and energy-intensive industries makes it possible to more flexibly keep operational parameters of work processes.

Keywords: post, router, power plant, generator, engine, server, automatic voltage regulator, network, module, regulator, actuator.

\author{
Брежнев Владислав Игоревич \\ Инженер-электроник, ЛРНУООО «Транснесть- \\ Балтика», г. Санкт-Петербург \\ vladyslav.brezhnev@yandex.ru
}

Аннотация. В статье приведен обзор раскрытия современных возможностей сетевого управления всей судовой энергетической установкой с использованием разнородных сетей, DUAL LAN, FIBER OPTIC, DUAL CAN, Modbus, так и отдельных элементов агрегатов посредствами сетевых возможностей через центральный пост, пост машинного отделения, дополнительные посты, пост энергохозяйства. Обоснована необходимость использования сетевого управления, для плавного регулирования технологического процесса посредствам контрольно-измерительных приборов, исполнительных механизмов, подключенных к контрольным модулям.

Показаны современные особенности применения сетевого контроля двух-тактного двигателя без распредвалов работающего на винт, где вместо распределительного вала используются электромагнитные актуаторы и четырех-тактного с использованием современной винто-рулевой колонки на базе азипод, где электродвигатель расположен в гандоле, что позволяет сделать гибким контроль винта, генераторов и двигателей с использованием разнородных сетей. Использование серверно-сетевых технологий в энергетических установках и энергоемких отраслях позволяет более гибко держать режимные параметры рабочих процессов.

Ключевые слова: пост, маршрутизатор, энергетическая установка, генератор, двигатель, сервер, автоматический регулятор напряжения, сеть, модуль, регулятор, актуатор.

чены цели и задачи судостроения Российской Федерации[6].

Например, в водном транспорте на судне в корме устанавливают винты с поворотной лопастью или винторулевую(-ые) колонку(-и) азипод. Анализируя современное состояние применения серверно-сетевых технологии, которые показаны на рисунке 1 позволяют сделать гибким контроль винта, генераторов и двигателей с использованием разнородных сетей, DUAL LAN, FIBER OPTIC, DUAL CAN, Modbus. Центральный пост, дополнительные посты взаимосвязаны с постами машинного отделения и постом энергохозяйства с помощью маршрутизаторов высокоскоростными оптоволоконными каналами.

Все контрольно-измерительные приборы и исполнительные механизмы подключены к контрольным модулям, которые в свою очередь передают данные 


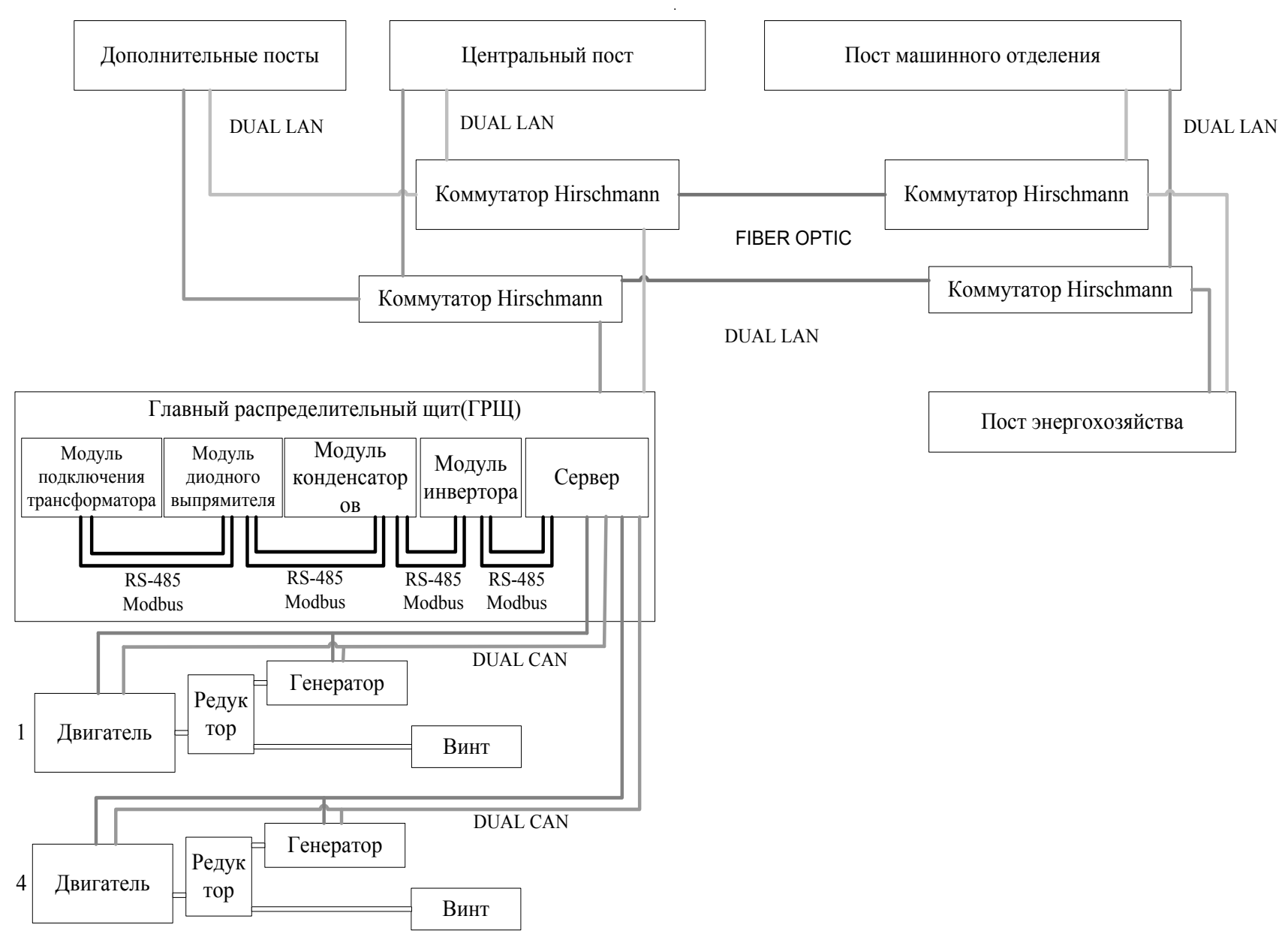

Рис. 1. Серверно-сетевое управление прямо на винт.

на сервер. Передача данных между модулями, сервером и постами реализуется через транспортный протокол ТСР. Для установления соединения модуль передает специальный ТСР-сегмент, потом сервер передает модуль специальный ТСР-сегмент, затем модуль передает третий ТСР-сегмент после этого соединение установлено. Когда соединение установлено модуль и сервер могут передавать данные.

Для модулей, серверов, постов применяется статическая маршрутизация, которая заставляет передавать заданные маршруты по указанному пути от источника к приемнику. Маршруты прописываются через стандартные приложения Windows: командная строка или WindowsPowerShell через следующую команду: route $-\mathrm{p}$ add 190.163.1.0 mask 255.255.253.0 192.168.1.1, где 190.163.1.0 адрес приемника куда передаются данные[1].

Используя сетевой контроль двигателем рисунок 2 при работе судна на винтовой тяге позволяет ступенчато изменять обороты двигателя при использовании че- тырех-тактного двигателя путем снижения/увеличения подачи топлива.

Использование двух-тактного двигателя без распредвалов работающего на винт, где вместо распределительного вала используются электромагнитные актуаторы, которые контролируют положение клапанов на открытие и закрытие и опрашиваются 105 раз в секунду в основе актуатора лежит датчик положения и пневматическая пружина. Помимо снижения/увеличения подачи топлива можно отключать подачу топлива в отдельные цилиндры, что позволяет снижать и увеличивать мощность двухтактного двигателя, при этом подача смазки в цилиндры не прекращается. Все актуаторы на двухтактном двигателе подключаются к блоку главного контроллера, где прописаны постоянные: скорость подъема, скорость опускания, время ожидания, количество циклов[3,4].

Передача данных от актуаторов реализуется по Dual CAN, так как скорость менее 1 Мбит/с, с широким диапазоном рабочих температур $-40+125$ ОС, хорошей устойчивостью к воздействию внешних разрядов, так как 


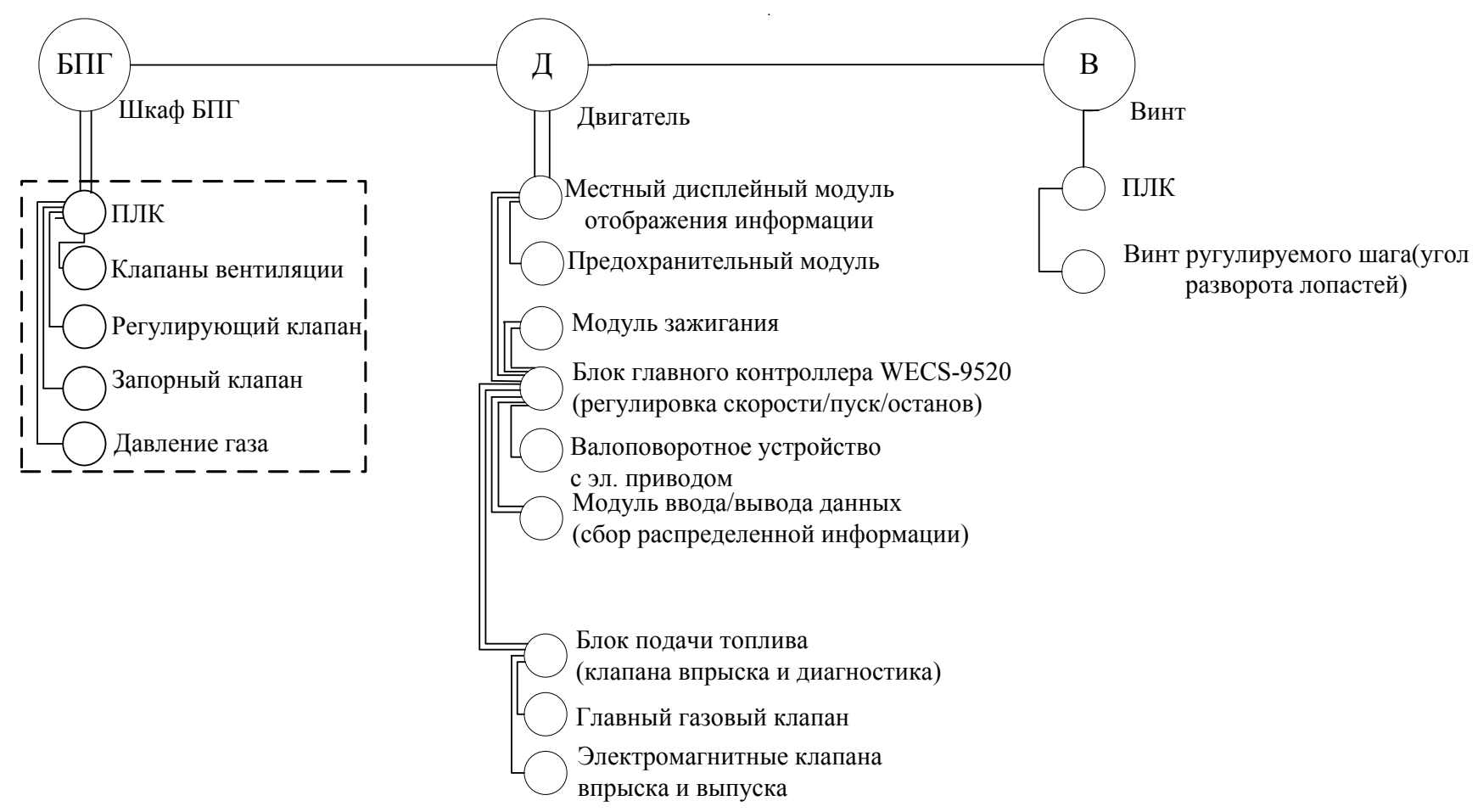

Рис. 2. Элементы модулей в агрегатах с двухтактным двигателем без распредвалов.

трансиверы CAN обладаю высокой надежностью. Данные по шине передаются сообщениями, где исключена всякая коллизия сообщений, т.е. несколько сообщений не могут отправиться одновременно, решается эта проблема путем ранжирования. Сообщения в DualCan имеют доминантное и рецессивное состояния. Сообщение с более высоким назначенным доминантным состоянием получают высокий приоритет будут продолжать передачу, а с низким приоритетом будут видеть доминирующий бит и прекратят передавать данные. Бит с низким приоритетом будет отправлять повторно сообщение до тех пока не передаст и он будет иметь доминантное состояние[2,5].

Для мониторинга каждого двигателя применяется управляющая мощность 24 В постоянного тока для каждого двигателя, которая используется для работы электронной схемы управления и для подачи питания на электромагнитный клапан стартера и магнитный пусковой выключатель. В нормальных условиях схема двигателя работает; все, что нужно, это приведение в действие электромагнитного клапана стартера. Двигатели не могут быть запущены или поддерживать работу без подачи 24 В постоянного тока на систему управления. Органы управления двигателем и индикаторы: индикаторы местного двигателя (на панели местного управления): мощность ввиде алармов сигнализаций; скорость двигателя (об / мин); давление моторного масла; температура выхлопной трубы; температура охлаждающей жидкости; расход топлива; процент мощности; часы работы двигателя; индикатор воздушного фильтра (на воздушном фильтре); напряжение аккумулятора (зарядное устройство).

Местные органы управления двигателем включают (на локальной панели управления): селектор меню; кнопка запуска; стоп кнопка; включить; аварийная остановка (топливный соленоид).

Индикаторы двигателя распределительного щита включают (VCS): Мощность в виде алармов; скорость двигателя (об/мин); давление моторного масла; температура выхлопной трубы; напряжение батареи; температура охлаждающей жидкости; расход топлива (л / час); процент мощности; часы работы двигателя.

Индикаторы двигателя распределительного щита включают (на распределительном щите): нагреватель вкл; работающий двигатель; общая сигнализация двигателя. Органы управления двигателем в помещении распределительного щита включают (на распределительном щите): сброс защиты в виде ключевого переключателя; нагреватель генератора вкл / выкл.

Электроэнергия на борту вырабатывается двумя ABB AMG1600 10,5 кВ переменного тока, 50 Гц, 3 фазы, с трехфазным генератором, вырабатывающим 22,9 кВА каждый. Генераторы приводятся в движение двумя 18-ци- 
Таблица 1

\begin{tabular}{|l|l|l|}
\hline Точность регулирования напряжения & \pm 0.5 & $\%$ \\
\hline - в пределах диапазона мощности & $0-100$ & $\%$ \\
\hline - в пределах диапазона оборотов & $95-105$ & $\%$ \\
\hline Диапазон задания напряжения & $90-110$ & $\%$ \\
\hline
\end{tabular}

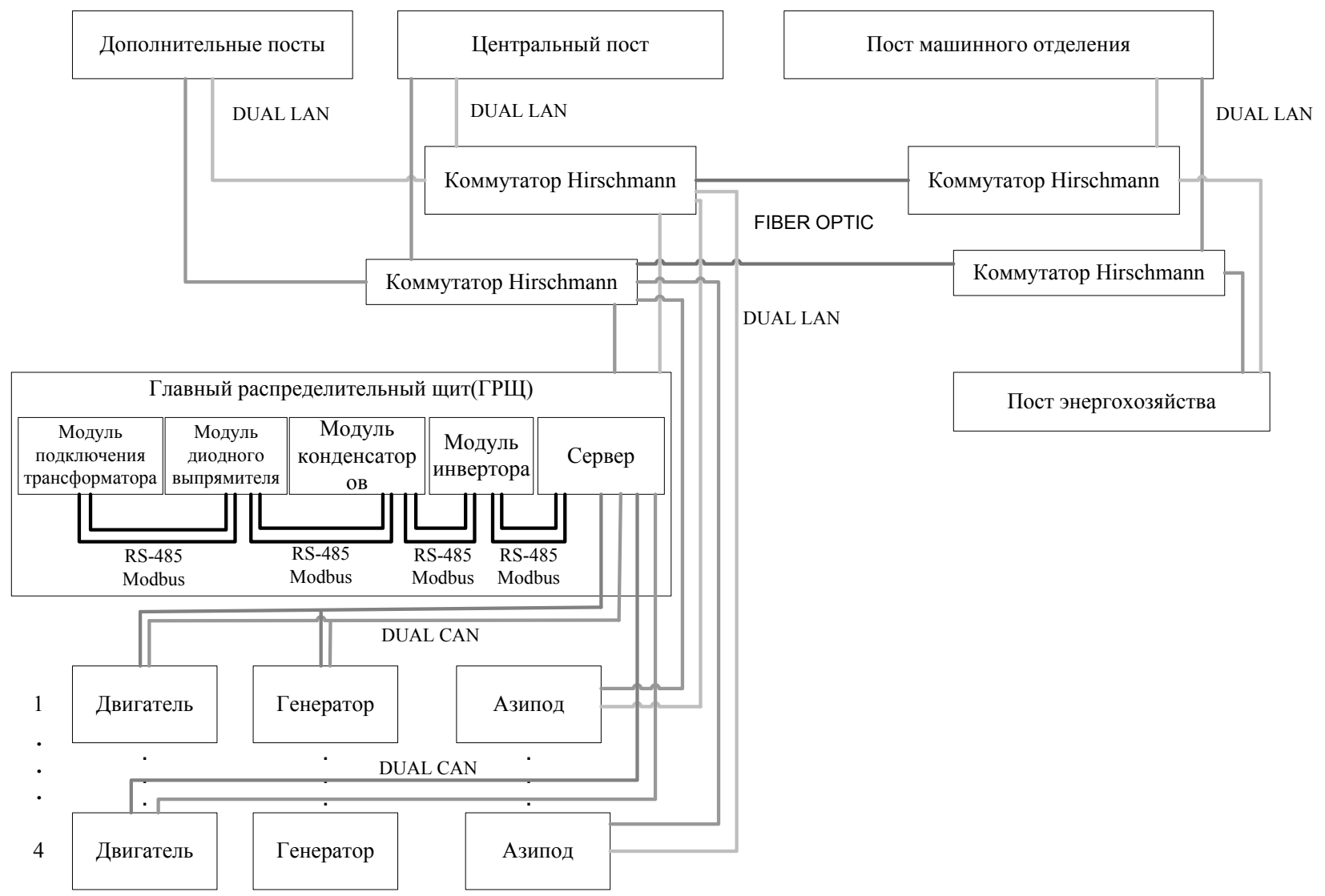

Рис. 3. Элементы модулей в агрегатах с четырехтактным двигателем при работе на винто-рулевую колонку азипод.

линдровыми главными двигателями WARTSILA 18V50DF, работающими на скорости 500 оборотов в минуту (об / мин).

Регулятор электронного модуля управления (ЕСМ) на каждом двигателе контролирует скорость двигателя, которая определяет частоту выходного сигнала генератора. Номинальная рабочая скорость составляет 500 об / мин, что дает частоту 50 Гц. Регуляторы управляют двигателями в режиме понижения, под контролем системы управления судном (VCS) / системы управления питанием (PMS), таблица 1.

В каждом генераторе встроен автоматический регулятор напряжения, который контролирует выходное напряжение генератора, регулируя величину тока от ге- нератора с постоянным магнитом, который подается на поле возбудителя, которое наматывается на статор. Поле возбудителя вызывает ток в якоре возбудителя, который намотан на ротор. Трехфазный диодный выпрямитель, установленный на роторе, преобразует ток якоря возбудителя в постоянный ток для вращающегося основного поля генератора[7].

Используя современную винто-рулевую колонку на базе азипод, где электродвигатель расположен в гандоле позволяет получить лучшую управляемость судна, которая может поворачиваться на 360 градусов при полном контроле (система рулевого управления или автопилот) или без контроля (местный щит) с помощью трех электрических двигателей рулевого управления и двух преобразователей частоты. Электронный блок 
управления обрабатывает сигналы, поступающие либо от системы управления рулевым управлением, либо от локальных неконтролируемых кнопок (местный щит), а также индикации направления тяги, журнала скорости и индикации уровня тяги и передает сигналы на три рулевых двигателя. Двигатели рулевого управления будут приводиться в движение электронным блоком управления через один из двух приводов с переменной частотой, пока не будет достигнуто выбранное направление тяги. Кнопки сброса преобразователя частоты находятся на главном шкафу. Для изменения направления тяги на 180 градусов требуется приблизительно 14 секунд в зависимости от скорости.

Крутящий момент силового двигателя уменьшается на высоких скоростях (> 8 узлов) и крайних углах пово- рота (> 35 градусов), чтобы предотвратить перегрузку силового двигателя. Ограничение крутящего момента силового двигателя не сигнализируется системой мониторинга тревоги судна или на пульте управления. Если азипод постоянно находится в положении «впереди», крутящий момент азипода может быть увеличен до максимального крутящего момента (100\%)[3].

Данный с блоков судовой энергетической установки поступают на сервер сбора данных на основе операционной системы Windows Server 2012 с программным пакетом SCADA через конвектор, откуда данные распределяются через маршрутизаторы на посты. На постах установлены клиенты или программные продукты Citrix, которые позволяют виртуализировать посты и запускать программные пакеты на любом из постов.

\section{ЛИТЕРАТУРА}

1. Куроуз Д., Росс К. Компьютерные сети: Нисходящий поток / Д. Куроуз, К. Росс — 6-е изд.— Москва: Издательство «Э», 2016. —912 с.

2. Хант К. ТСР/ІР. Сетевое администрирование, 3-е издание. Пер. с англ./ К. Хант — СПб: Символ-Плюс, 2007. — 816 с.

3. Виноградов А. А. Распределение нагрузки при параллельной работе судовых дизель-генераторных агрегатов сучетом расхода топлива / А. А. Виноградов, С. Е. Кузнецов // Сб. тезисов докладов национальной ежегодной научно-практической конференции профессорско-преподавательского состава ГУМРФ имени адмирала С. О. Макарова.— СПб.: Изд-во ГУМРФ им. адм. С. 0. Макарова, 2017.- С. 21-22.

4. Шестопалов, М. Ю. Отказоустойчивое управление циклическими многостадийными технологическими процессами / М. Ю. Шестопалов // Инновации.2015. — № 4 (198). - - C. 8-12.

5. Сахаров В. В. Автоматизация поиска оптимальных маршрутов и грузовых потоков в транспортных сетях средствами целочисленного линейного программирования / В. В. Сахаров, И. А. Сикарев, А. А. Чертков // Вестник Государственного университета морского и речного флота имени адмирала С. 0. Макарова.—2018. - № $3(10)$. - С. 647-656.

6. Государственная программа Российской Федерации «Развитие судостроения на 2013-2030годы».URL.: http://www.consultant.ru/document/cons_doc_LA W_155198/3ecab266ad8cb0a9e1c074c2eeb5c55f1cb2934f/(дата обращения: 16.03.2020).

7. Сайт компании ABB URL.: https://new.abb.com/ (дата обращения: 16.03.2020). 